\title{
94-MP21.06
}

\section{The Effect of Contaminant Aging Upon Soil Washing Removal Efficiencies for Lead Contaminated Soils}

\author{
Steven R. Cline \\ Environmental Sciences Division \\ Oak Ridge National Laboratory \\ Oak Ridge, Tennessee \\ Brian E. Reed and Roderic E. Moore \\ Wesi Virginia University \\ Morgantown. West Virginia

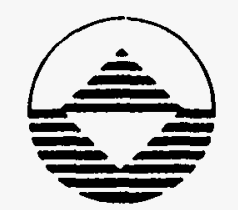

\section{DISCLAIMER}

This report was prepared as an account of work sponsored by an agency of the United States Government. Neither the United States Government nor any agency thereof, nor any of their employees, makes any warranty, express or implied, or assumes any legal liability or responsibility for the accuracy, completeness, or usefulness of any information, apparatus, product, or process disclosed, or represents that its use would not infringe privately owned rights. Reference herein to any specific commercial product, process, or service by trade name, trademark, manufacturer, or otherwise does not necessarily constitute or imply its endorsement, recommendation, or favoring by the United States Government or any agency thereof. The views and opinions of authors expressed herein do not necessarily state or reflect those of the United States Government or any agency thereof.

For Presentation at the 87th Annual Meeting \& Exhibition Cincinnati,Ohio June 19-24, 1994
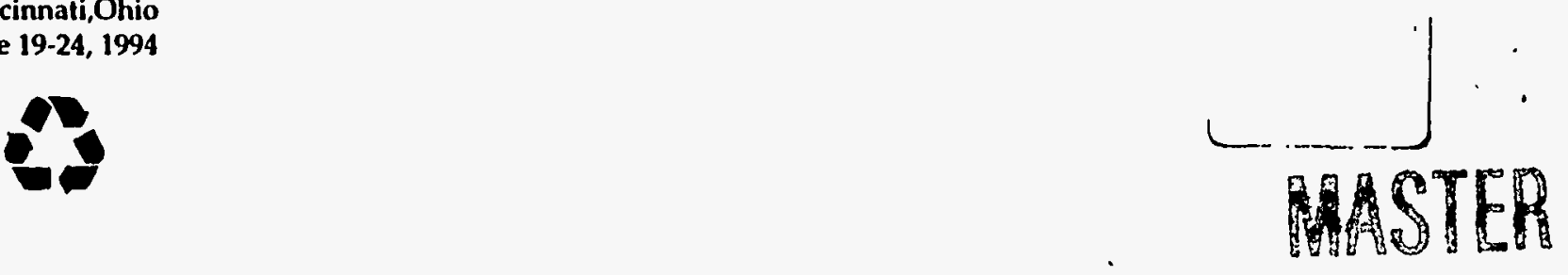


\section{DISCLAIMER}

Portions of this document may be illegible in electronic image products. Images are produced from the best available original document. 
Soil washing has recently become a popular ex-sttu lechnique for remediating sites contaminated with heavy metals This research focused on lead contamination. since lead is one of the most common heavy metals at Superfund sites across the nation ${ }^{\prime}$ Lead is commonly found at sites where past industrial activities include battery breaking and recycling. oil refining. paint manufacturing, metal molding and plating. and smelting Lead pollution from the automobile industry is also extensive The objective of this research was to investigate lead removal efficiencies from various soils using a variety of washing solutions Most soil types have a strong affinity for lead Thus, it is plausible to expect washing solution that are capable of removing lead could also remove other divalent heavy metals

Like most bench scale soil washing studies, the soils used here were artificially contaminated with lead Spiking soils in such a manner can offen reduce the heterogeneily in initial contamination levels often observed in soils from actual contaminated sites As with' any experimental work, lab conditions cannot perfectly mimic natural conditions. Soils that have been contacted with heavy metals in nature are oflen more difficult to remediate than soils spiked in the laboratory, for the stronger retention mechanisms ( $1 . e$. specific adsorption. solid state diffusion and precipitation) occur slowly over a periods of many years? For example, metal oxides in nature are often initially amorphous and found as coatings on other soil components such as sands With time, however. these amorphous minerals will develop crystalline patterms which retain heavy metals very rightly In a kinetic release study, lead release was observed to be a two step process, with the initially rapid removals being associated with weak retention mechanisms such as cation exchange The second phase of lead release, most likely of the stronger bound lead. occurred at a much slower rate Reaction rates obtained for artificially contaminated soils in the same study were al least an order of magnitude greater than that of the naturally contaminated soil?

Four (4) soil samples from the eastem Uniled States were collected and characterized for this study The study soils were then spiked to approximate lead concentrations of 1,000 , and $10,000 \mathrm{mg} \mathrm{Pb} / \mathrm{kg}$ soil The efficiencies of six washing solutions in removing lead from the contaminated soils were then investigated via lab-scale batch washing experiments Unlike current field-scale soil washing practices, all particle size fractions were washed and recovered in these experiments (Solutions investigated include: tap water. $\mathrm{HCl}, \mathrm{EDTA}, \mathrm{HNO}_{3}, \mathrm{CH}_{3} \mathrm{COOH}$, and $\mathrm{CaCl}_{2}$ ) In order to examine the effect of aging upon soil washing efficiencies, some of the spiked soils were washed a second time after an aging period of nearly 2 years

\section{MATERIALS AND METHODS}

Experimental work was performed at the WVU Environmental Engineering laboratories All chemicals used were reagent grade Solutions were prepared in nitric acid insed volumelric flasks then stored in polyethylene containers. To minimize chemical biodegradation, organic reagents, such as EDTA or acetic acid were refrigetated prior to use Measurements of $\mathrm{pH}$ were obtained using Orion ${ }^{\text {tw }}$ meters and combination electrodes. All samples for lead analysis were filtered through a $045 \mu \mathrm{m}$ membrane filter and were preserved by acidification with nitric acid if the $\mathrm{pH}$ of the filtrate wis greater than 20 All wash experiments were conducted in triplicate The filter assembly and the $\mathrm{pH}$ electrode were rinsed between Iriplicates in order to reduce the possibility of sample contamination Lead concentrations were determined using a Perkin Elmer 2380 ${ }^{\text {tw }}$ atomic absorption spectrophotometer (A A) equipped with a flow spoiler. The andyses were performed using an air-acelylene flame and wavelenglh seltings of $\lambda=$ $2170 \mathrm{~nm}$. Percent recoveries were performed on approximately I in every $S$ samples to ensure that significant interferences were not present
Soil Spiking Procedure

Each study soil was spiked with lead at two (2) different concentrations if complete adsorption of lead from solution were to occur, this contamination procedure would yield soil concentrations of 1,000 and $10,000 \mathrm{mg} / \mathrm{kg} \mathrm{Pb}$ above indigenous soil lead concentrations A 10 I liquid soil ratio was employed in the contamination step Solutions of lead nitrate $\left[\mathrm{Pb}\left(\mathrm{NO}_{3}\right)_{2}\right]$ were prepared baving approximate lead concentrations 100 and $1,000 \mathrm{mg} / \mathrm{L}$ Sodium nitrate $\left(\mathrm{NaNO}_{3}\right)$ was also added to each solution to simulate the ionic strength ( $\mu$ ) of groundwater As a result, all lead solutions were prepared with a $\mathrm{NaNO}_{3}$ concenisation of $3,200 \mathrm{mg} / \mathrm{L}$ ( $\mu=004$ Moles $/$ )

One hundred fifty grams of air-dried. No 10 sieved, soil was placed in a 2 liter Nalgene ${ }^{\text {Tw }}$ container with I 5 liters of the appropriate $\mathrm{Pb}$ - NaNO, solution An aliquot of each $\mathrm{Pb}-\mathrm{NaNO}_{3}$ solution. taken prior to the addition of soil, was acidified and kept for lead analysis Initial slurry pH's were taken. and the samples were placed on mechanical shakers for twenty one (21) days To reduce the possibility of lead precipitation, the $1,000 \mathrm{mg} / \mathrm{L}$. $\mathrm{Pb}$ contaminating solution was $\mathrm{pH}$ adjusted to 48 with nitric acid (HNO $)$ ) before being mixed with the soil At the end of the contacl period, the samples were not disturbed for 24 hours in order to provide adequate time for the colloidal clay particles to settle. The superme subsequent mass balance calculations A small aliquot of the supermatant was taken, $0.45 \mu \mathrm{m}$ filtered, and preserved for lead analysis The remaining soil was then air dried and crushed to pass through an ASTM No. 10 sieve Two methods were used to determine the final contamination levels The first method was based upon mass balance principles It was assumed all lead removed from solution was retained by the soils. Hence, the amount of lead retained by the soil was determined via the difference between the lead concentrations of the initial $\mathrm{Pb}-\mathrm{NaNO}_{3}$ solution and supernatant solution according to the following equation

Soil $\mathrm{Pb}=\left\{\left[\mathrm{Pb}_{0} \cdot \mathrm{V}_{0}\right]-[\mathrm{Pb} \rho \mathrm{V} /]\right\}+\left[\mathrm{W}_{\mathrm{s}}\right]$

Where:

$\mathrm{Pb}_{\mathrm{a}}=$ Initial Pb Concentration.

$\mathrm{Pb} f=$ Final Pb Concentration

$V_{0}=$ Initial Volume Pb Solution

$V_{f}=$ Superinatani Volume.

W. $=$ Weight Soil Added

As a check, a second method was used where the contaminated soils were digested in triplicate for lotal metul contens using EPA Method 30504 The average of these two values was used as the initial lead value during the washing experiments uniess otherwise noted.

\section{Laboratory Washing Experimeats}

The study soils, contaminated with two concentrations of lead, were washed in triplicate with the solutions listed in Table I In these batch experiments, $25 \mathrm{~mL}$ of each washing solution was delivered (via s wide-mouth volumetric pipette) into a $60 \mathrm{~mL}$. Nalgene ${ }^{\mathrm{Ts}}$ bottle that contained $10 \pm 002$ grams of contaminuted soil The samples were then placed on mechanical shakers for 24 hours.

Al the end of the 24 hour period, the pH of the cach sample slurry was measured and recorded. Approximately $10 \mathrm{~mL}$ of each sample was then vacuum filtered through a $045 \mu \mathrm{m}$ membrane filter. The remaining portion of the sample was rinsed from the sample bollte and discarded in a waste container The resulting filtrate was placed back into the same bottle, preserved if required, and kept for lead 
analysis Atomic absorption results represented the quantity of lead removed from the contaminated solls and wes divided by the initial lead mass on each soil (determined earlier via both acid digestion and the mass balance approach described above) to oblain soil washing efficiencies The portion of each spiked soil not used in the first wash was stored in sealed containers and allowed to age To investigate the effects of aging, the soils were then washed in the same manner as the original washes described above

\section{RESULTS AND DISCUSSION}

Characterization data determined for the study soils used in the aging experiments are presented in Table 2 Soils $I$ is sandy in nature while Soils 2 is much finer grained Subsequently. Soil 2 possesses a greater CEC value and a higher organic content typically of finer grained soils It was thought that the selection of these soils would not only provide insight into the effect of aging but might also provide data illustrating the effect of soil type upon washing efficiencies

The butch soil washing experiments were first conducted 2 months after the soils were artificially contuminated with lead Additionally, wash experiments were conducied on a second sample of each contaminated soil 20 months after soil spiking The wash results for Soil $I$ are presented in Figures 1 and 2 for the low and high lead spiking levels, respectively. Similarly. Figures 3 and 4 present the wash results for Soil 2 at the low and high lead contamination level The initial lead contamination level (as discussed in

previous section) is also provide on each plot The values plotted in these figures represent the average of triplicate washes Reproducibility among triplicate samples were generally very good One notable exception was for the $\mathrm{O}$ IN HNO ${ }_{3}$ wash of Soil I (see Figure I), where the triplicate samples yielded a range of lead removals from 61 to 144 percent The results of the tap water washes are included in Figures $1-4$ to illustrate that the lead was not readily removed from any of the soils even though a soluble Figures $1-4$ to illustrale that the lead was not readin was used in the spiking procedure
lead

As expected, the greatest removals were obtained from the acid washes ( $\mathrm{HCl}$ and $\mathrm{HNO}_{3}$ ) and the EDTA washes A more detailed discussion of the $\mathrm{HCl}$ and EDTA washes performed as part of this study can be found elsewheres Considerably lower removals were obtained by the acetic acid and calcium chloride washes. Removals achieved by strong acid solutions are likely due to dissolution of some of the soil components, thereby releasing lead was originally bound by cation exchange, specific adsorption, and other stronger retention mecharisms. Allhough some chloride ions may complex with soil bound lead, cation exchange is most likely the dominant removal mechanism that is operative during the $\mathrm{CaCl}_{2}$ washes. (The excess $\mathrm{Ca}^{2+}$ cutions invoke a concentration gradient that forces the exchange of $\mathrm{Pb}^{2+}$ ions for $\mathrm{Ca}^{2+}$ ions on the soil surface sites) The concentration of the washing solutions also had an effect upon the $\mathrm{CH}_{3} \mathrm{COOH}$ and $\mathrm{CaCl}_{2}$ samples, where removil efficiencies increased markedly with increases in washing solution atrength.

Figures 1-4 present the dats from both washes of each soil It is evident that removal efficiencies decreased for many of the samples as a result of the "aging" process This phenomenon was the greatest for the $\mathrm{HCl}$ and EDTA washes whese the average removal were 8 percent less for the samples aged 20 months than for the soils aged 2 only months In addition, the effect of aging is more pronounced for the
mong samples spiked at the lower lead level than at the higher lead level for both study soils (The effect of initial contamination level upon removals will be discussed later)

For each soil and lead contamination level, the removal efficiencies obtained for the acetic acid washes appear to be essentially identical for the 2 month and 20 month washes (See Figures 1-4)
Results of other research indicate that the ability of acetic acid to decrease heavy metal retention by soils is limited By definition, acetic acid is not a chelating agent, but acetic acid can form weak complexes with heavy metals Cadmium-adsorption experiments using a sill loam (1125 mg/kB Cd) with characteristics similar to Soil 2 were performed in the presence of $20 \times 10^{-2} \mathrm{~N}$ acelic acid and then in the characteristics $0 \times 10^{6} M E D T A$ the (as compared 10 conisols samples with no complexing ligands present) was found to be $50 \%$ for EDTA (as compared to controls samples with no compl
but only $5 \%$ for the acetic acid experiments

Even though acetic acid is a weak complexing agent, it most likely mobilizes soil bound lead via its ability to lower the pHl of a soil system Acetic acid is a weak acid which dissociates at pH 475 (pKa value) The un-ionized form dominates at $\mathrm{pH}$ 's below the $\mathrm{pK}$ value The slurry $\mathrm{pH}$ values taken at the end of the wash experiments (pnor in filtering) were all below the $\mathrm{pK}_{\mathrm{a}}$ value Thus, the neutrally charged species $\left(\mathrm{CH}_{3} \mathrm{COOH}\right)$ may have been adsorbed by the soils, thereby lowering the system pH and reducing the number of surface sites gvailable for heavy metal retention The observation that the acetic acid removals were seemingly not affected by soil aging could possibly be explained by the fact that the slurry $\mathrm{pH}$ reduction induced by acetic acid was not great enough to release any more lead from the "newly" spiked samples than it was capable of releasing from the aged soils

In contrast to all other washing solutions investigated, nearly all calcium chloride removals were greater for the aged samples, in fact, the average removals from the 20 month samples were 13 percent greater than from the samples aged only 2 months. It is suspected that this situation is caused by the pH values of the $\mathrm{CaCl}_{2}$ slurries Unlike the other washes which typically had slumry $\mathrm{pH}$ values less than $4 \mathbf{0}$. pH values for the $\mathrm{CaCl}_{2}$ slurries were generally in the range of $5 \mathrm{s.62}$ Al such high $\mathrm{pH}$ values, surface precipitation reactions may be occurring that increase enhance lead retention In experiments involving an aqueous solution of $100 \mathrm{mg} / \mathrm{L} \mathrm{Pb}$ with ionic strength used in the contaminating slurries $(\mu=004 \mathrm{M})$. significant quantities of lead began to be removed from solution at a pH of $6^{7}$ In addition, the presence of a solid phase typically decreases the $\mathrm{pH}$ at which lead is removed from solution (via precipitation and other tdsompion reactions) The $\mathrm{CaCl}_{2}$ solutions prepured for the 20 month experiments had slightly lower initial $\mathrm{pH}$ values than those prepared for the washes conducted 2 months after spiking This anomaly resulted in slurry pH values after the 24 hour wash period to be approximately $02.04 \mathrm{pH}$ units anomaly resulted in slurry pH values after the 24 hour wash period to be approximately $02.04 \mathrm{pH}$ units
less for the 20 month samples than for the 2 month samples Such a small decrease in pH can lead to drastic increases in lead mobility in situations where conditions, as predicted here, are conducive to surface precipitation reactions

The soil washing dala presented here also illustrated other factors in addition to contaminant aging that affected removal efficiencies. It has been known that lead is less tighlly bound to soils when present at high initial concentrations, for lead cations are preferentially setained by the high energy binding sites (reactive surface sites) when lead is present in trace quantities As more lead is added to the soil, the (reactive surface sites) when lead is present in trace quantities As more lead is added to the soll, the the high energy siles have already been filled. Such a trend was observed in this study The average removal efficiency for Soil $I$ in Figure 1 (average of all wash solutions except tap water) was 66 percent. while the average lead removal from the samples spiked at the higher lead level (Figure 2) was 82 percent (16\% grealer) The difference between removal efficiencies was slightly less for Soil 2 The average removal efficiency for Soil 2 in Figure 3 was also 66 percent, while the average lead removal from the samples spiked at the higher lead level was 71 percent (5\% greater) The cffect of initiel concentrion samples spiked at the higher lead level was 71 percenl (S\%, whener) The effect of richel concentration. however, would not be expected to be as great for Soil 2 Due to its larger organic content and greater Soil I Note, however, that the lower removal efficiency of Soil 2 compared to Soil 1 at the higher lead 
conlamination level (71\% $15.82 \%$ ) could also be due to the fact that the initial lead concentration of Soil 2 is much larger than that of Soil I ( $9110 \mathrm{mg} / \mathrm{kg}$ vs. $2680 \mathrm{mg} / \mathrm{kg}$ ) whose lead setention capacily was probably not reached during the 21 day contamination period (Retention kinetic studies have suggested that surface precipitation, which is a slower retention mechanism than cation exchange, etc., may have been the dominant retention mechanism for Soil 1$)^{9}$

\section{CONCLUSIONS}

Although the aging study did not yield enough data to support a thorough statistical analysis, the results obtained do illustrate the effect that several factors have upon the effectiveness of soil washing to remediate lead and possibly other heavy metal contaminated soils These factors include contaminant remediate lead and possibly ol cor concentration, soil type; and initial contaminant concentration of the aging; washing solution type and concentration, soil type; and initial conteminant concentration Of the
washing solutions investigated, the effect of aging was most apparent for the HCI, EDTA, and HNO, washing solutions investigated, the effect of aging was most apparent for the HCl, EDTA, and HNO,
washes, particularly for the samples contaminated at the lower lead level $(\approx 1,000 \mathrm{mg} / \mathrm{kg})$ In addition removals via the acetic acid and calcium chloride washes were generally low, similar or increased removals being oblained for the aged soil samples Such an occurrence is suspected to be due to the characteristics/properties of these washing solutions, rather than a inue reduction in the strength of lead retention to these soils after a 20 month period of aging

\section{ACKNOWLEDGMENTS}

The submitted manuscript has been authored by a contractor of the U S Government under contract DEAC05-840R21400 Accordingly, the U S Government retains a non-exclusive, royalty-free license to publish or reproduce the published form of the contribution, or allow others to do so, for U S Government purposes The author would also like to express his appreciation for the efforts of con authors Brian Reed and Rod Moore and his laboratory assistants at West Virginia University.

\section{REFERENCES}

I Superfund Engineering Lssue: Treatment of Lead Contrminuted Soils. EPA540/2-91/009, U S Environmental Protection Agency, Office of Solid Waste and Emergency Remedial Response, Washington, D.C, 1991

2. B J. Tuin and M Tels, "Distribution of Six Heavy Metals in Contaminated Clay Soils Before and Afler Extractive Cleaning," Environmental Technology, I1, 935-948 (1990)

3. B.J. Tuin and M. Tels, "Extraction Kinetics of Six Heavy Metals from Contaminated Clay Soils," Envirenmental Technolegy, 11, 541-554, 1990.

4. Iera Methods for Evaluating Solid Waste: Physical Chemical Methodss SW-486, U S. Environmental Protection Agency, Office of Solid Waste and Emergency Response, Washington, D C, 1986

S S R Cline and B E. Reed, "Lead Removal From Soils Vin Bench Scale Soil Washing Techniques," Submitted for publication to ASCE Joumal of Environmental Engineering December 1993.

6 H A Elliott and C M Denneny, "Soil Adsorption of Cadmium from Solutions Containing Organic Ligands," Joumel of Environmentil Ouality. 11(4), 658-663, 1982
94-MP21.06

7 B E Reed and S R Cline, "Retention and Release of Lead by a Very Fine Sandy Loam I Isotherm Modeling." Submitted for publication to Separation Science and Technology. December 1993

8 M M Benjamin and $\mathrm{O} O$ Leckie, "Multiple-Site Adsorption of Cd, $\mathrm{Cu}, \mathrm{Zn}$, and $\mathrm{Pb}$ or Amorphous Iron Oxyhydroxide," Journal of Colloid and Interface Science. 79(1), 209-221, 1981

9 S R Cline, "Efficiencies of Soil Washing/Flushing Solutions to Remediate Lead Contaminated Soils," MS Thesis, Department of (ivil and Environmental Engineering. West Virginia University.

Morgantown, WV. 1993

10 Annual Baok of ASTM Standards Soil and Rock. Dimension Stone, Geosynthetics, . American Society of Testing and Malerials, Easton, MD, vol 4 08, 1991 .

II Standard Methods for the Examination of Water and Wastewatec M.H Franson, ed, American Public Health Assocation, Washington, D C . 1985

$12 \mathrm{~J} \mathrm{~A}$ McKeague and $\mathrm{J} H$ Day, "Dithionite and Oxalate Extractable $\mathrm{Fe}$ and $\mathrm{Al}$ as Aids in Differentiating Various Classes of Soils," Canadian Joumal of Soil Science 46, 13-22, 1966

13 O P Mehra and MLL Jackson, "Iron oxide removal from soils and clays by a dithionite citrate sytem buffered with solium bicarbonate," in Clays and Clay Minerals, Proceedings of the Seventh National Conference. Earth Science Series: 317.327, 1960 
Table 1. Washing Solutions Investigated

\begin{tabular}{ll}
\hline \hline Washing Solutions & Concentrations \\
\hline Tap Water $\left(\mathrm{H}_{2} \mathrm{O}\right)$ & Nol Applicable \\
Hydrochloric Acid (HCl) & 0 I $\mathrm{N}$ and $1 \mathrm{ON}$ \\
Nitric Acid $\left(\mathrm{HNO}_{3}\right)$ & $01 \mathrm{~N}$ and $1.0 \mathrm{~N}$ \\
EDTA $\left(\mathrm{Na}_{2} \mathrm{C}_{10} \mathrm{H}_{14} \mathrm{O}_{8} \mathrm{~N}_{2} \cdot 2 \mathrm{H}_{2} \mathrm{O}\right)$ & $001 \mathrm{M}$ and $0.1 \mathrm{M}$ \\
Acetic Acid $\left(\mathrm{CH}_{3} \mathrm{COOH}\right)$ & $01 \mathrm{~N}$ and $1.0 \mathrm{~N}$ \\
Calcium Chloride $\left(\mathrm{CaCl}_{2}\right)$ & 0 i M and $1.0 \mathrm{M}$ \\
\hline
\end{tabular}

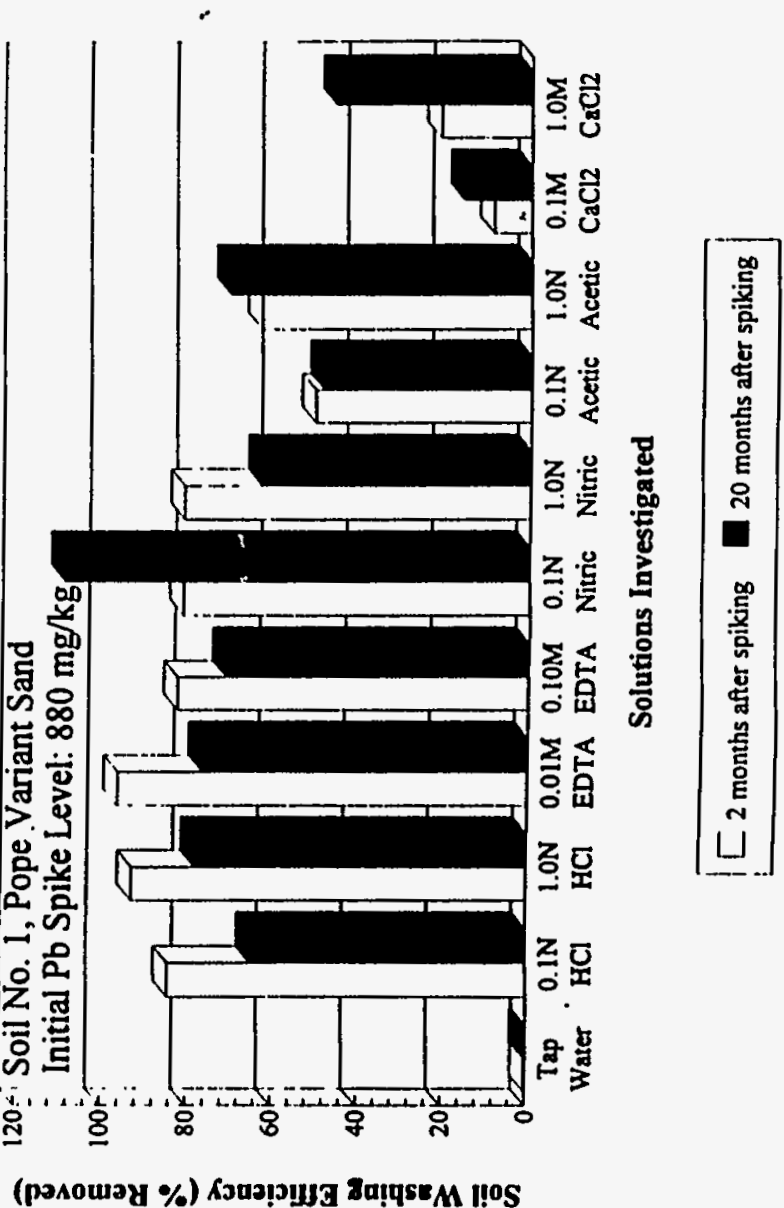

\begin{tabular}{|c|c|c|}
\hline Parameter & Soil No 1 & Soil No. 2 \\
\hline Soil pH 4 & $6.2 \pm 0.20$ & 7.01010 \\
\hline$\%$ Passing No 200 Sieve ${ }^{10}$ & 1.7 & 372 \\
\hline Indigenous $\mathrm{Pb}(\mathrm{mg} / \mathrm{kg})^{4}$ & $63 \pm 13$ & $19 \pm 1.5$ \\
\hline $\operatorname{CEC}\left(m_{e q} / 100_{B}\right)^{4}$ & $64 \pm 060$ & $205 \pm 20$ \\
\hline Tolal Volatile Solids (Wi \%) " & $160 \pm 010$ & $437 \pm 020$ \\
\hline $\mathrm{Fe}_{\mathrm{AAO}}\left(\mathrm{mg} / \mathrm{kg}_{\mathrm{B}}\right)^{12}$ & $1350 \pm 80$ & $5000 \pm 200$ \\
\hline$A_{D}(m g / k g){ }^{13}$ & $600 \pm 50$ & $2110 \pm 120$ \\
\hline $\operatorname{Mn}_{A A O}(m g / k g)^{12}$ & 52 & $515 \pm 10$ \\
\hline
\end{tabular}

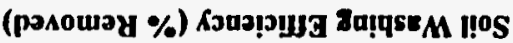




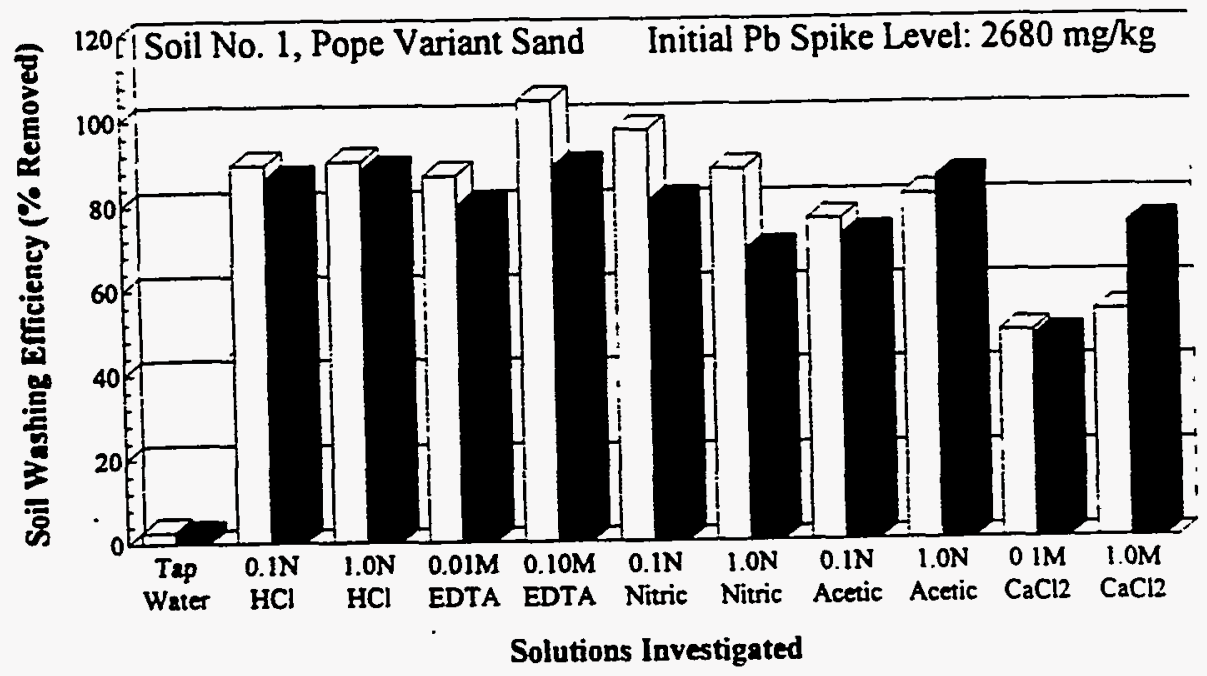

Figure 1 Soil Washing Results for Soil 1 Spiked at the High Lead Concentration Level

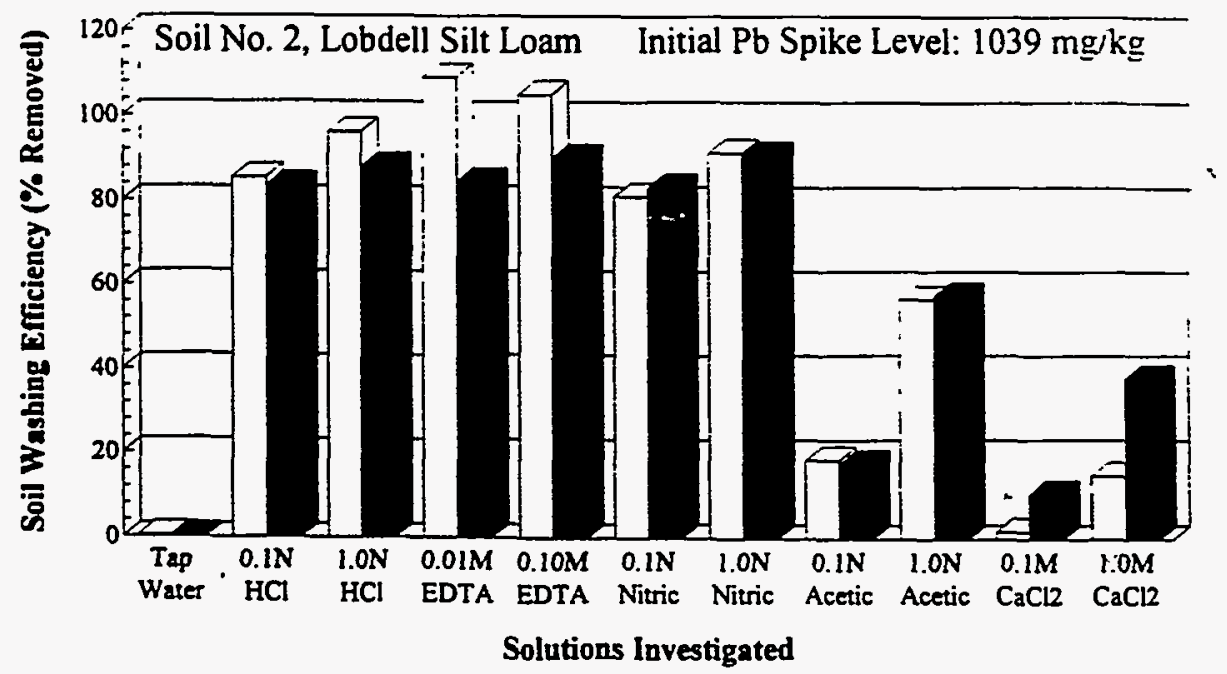

Figure I 


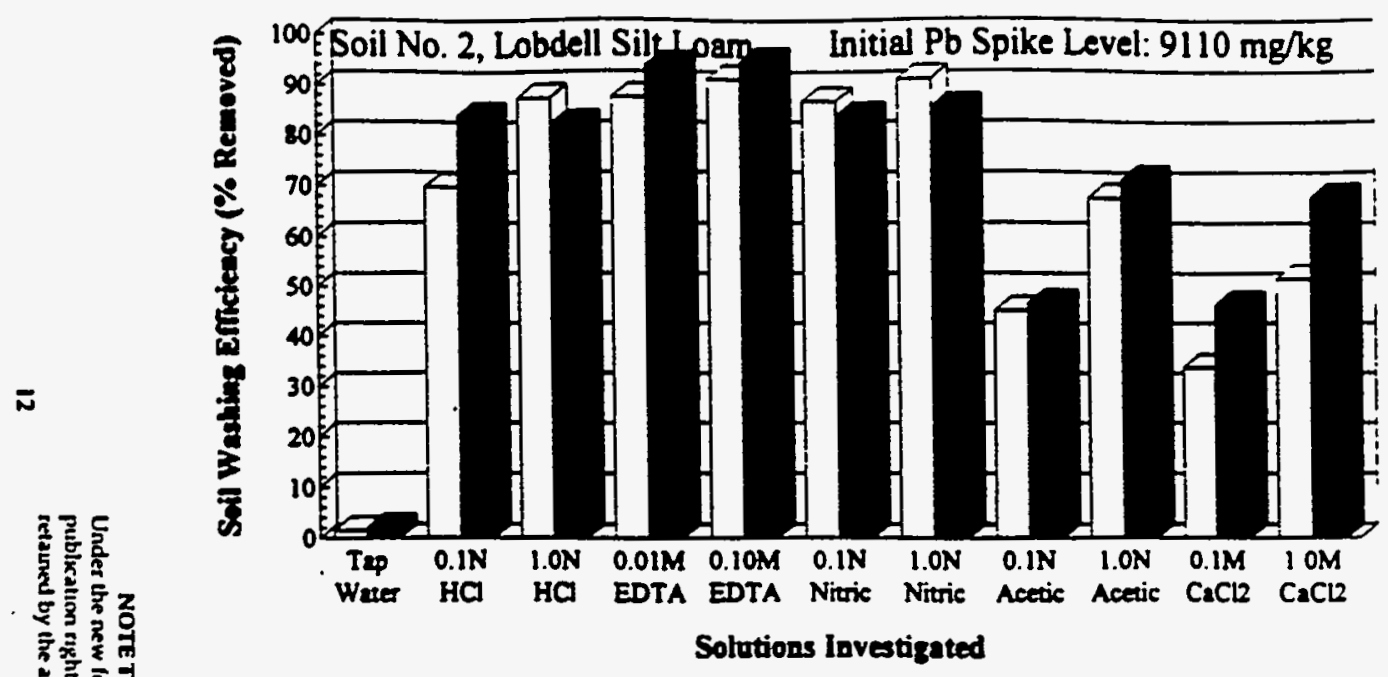

Figure 1. Soil Washing Resuths for Soil 2 Spiked a the High Lead Concentration Level

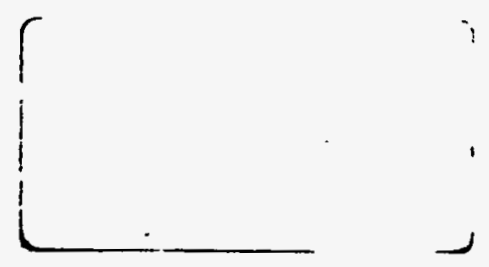

